$(\infty)$ EY

\title{
A COMPREENSÃO DOS PROFESSORES \\ DE EDUCAÇÃO FÍSICA SOBRE O CURRÍCULO \\ DO ESTADO DE SÃO PAULO: UM OLHAR \\ A PARTIR DAS ETAPAS DA CARREIRA DOCENTE
}

THE COMPREHENSION OF TEACHER

OF PHYSICAL EDUCATION ABOUT THE CURRICULUM

FROM THE STATE SAO PAULO: A LOOK

THROUGH THE STATES OFTEACHER CARRER

LA COMPRENSIÓN DE MAESTROS DE

EDUCACÍON FÍSICA EN EL PLAN DE ESTUDIOS

DE SÃO PAULO: UNA VISIÓN

DESDE LOS PASOS DE CARRERA DOCENTE Gabriel da Costa Spolaor ${ }^{1}$,
Jocimar Daolio

\begin{abstract}
RESUMO
Em 2010, foi criado, por intermédio da Secretaria de Educação do Estado de São Paulo, o Currículo do Estado de São Paulo (CEF-SP). Desde então, algumas pesquisas vêm se dedicando a estudar os impactos dessa implementação. Na tentativa de contribuir com novas observações, tivemos como objetivo geral nesta pesquisa analisara compreensão dos professores da Rede Estadual de São Paulo sobre o Currículo de Educação Física vigente, e de forma específica, considerar a relação dessa compreensão com as etapas da carreira docente dos professores. Como procedimentos metodológicos foram utilizadas entrevistas semiestruturadas. Pudemos perceber certo desenvolvimento na construção da carreira dos professores de Educação Física, não de forma linear, mas de acordo com as relações e experiências socioculturais com as quais cada um tomou contato. Todas essas características parecem influenciar a relação dos professores com o Currículo, visto que os sentidos dados, assim como as formas de utilização do material, variam de acordo com as necessidades e problemáticas encontradas em cada uma das etapas. Quando nos atentamos especificamente à compreensão dos conceitos teóricos presentes no currículo, foi possível perceber um entendimento pouco aprofundado por parte dos professores.
\end{abstract}

PALAVRAS-CHAVE: Educação física escolar. Currículo de São Paulo. Carreira docente.

\begin{abstract}
In 2010, was made by the Secretary of Education from the State São Paulo the Curriculum of State São Paulo (CEF-SP). Since then, some researches are trying to identify the impact of this implementation. To try to add to the new observations, we tried as a main goal on this research analyze the understand about the teachers of Physical Education from the State Schools about the document which has been applied, considering how that is related to this comprehension and the stages through the teacher career. As the methodologies procedures that has been use in semi-structures interview. We could see some development related to the steps through the teaching career of Physical Education, not in a linear form, but accord and related to the experiences that each one had been in touch during their one life. All those characteristics may influence how teacher are related to the curriculum, seeing that the sense gave, as the ways to use the materials, can have differences according to the needs and problems found in each step. When we look specifically to the comprehension of
\end{abstract}

\footnotetext{
${ }^{1}$ Universidade Estadual de Campinas - UNICAMP, Campinas, São Paulo - Brasil

Contato: gabriel.spolaor@hotmail.com

Submetido em: 18 dez. 2015 - Aceito em: 18 mar. 2016
} 
the theory concepts into the curriculum, was possible to realize a shallow and not deeply understood by some teacher.

KEYWORDS: Scholar physical education. Curriculum of São Paulo. Teacher career.

\section{RESUMEN}

En 2010, fue creado por el Departamento de Educación del Estado de São Paulo, el Plan de Estudios del Estado de São Paulo (CEF-SP). Desde entonces, algunas investigaciones se ha dedicado al estudio de los impactos de esta aplicación. En un intento de aportar nuevas observaciones, teníamos el objetivo general de esta investigación para analizar la comprensión de los profesores de la Rede Estatal de São Paulo en el actual plan de estudios de educación física, y en concreto, tenga en cuenta la relación de este entendimiento con las etapas de la carrera docente de profesores. Como instrumentos se utilizaron entrevistas semi-estructuradas. Pudimos observar cierto desarrollo en la construcción de la carrera de los profesores de Educación Física, no lineal, pero de acuerdo a las relaciones y experiencias que cada uno tomó contacto. Todas estas características parecen influir en la relación entre los profesores y el plan de estudios, ya que las instrucciones dadas, así como formas de utilizar el material, varían de acuerdo a las necesidades y los problemas encontrados en cada etapa. Cuando prestamos atención en particular a la comprensión de los conceptos teóricos presentados en el plan de estudios, se reveló poco entendido por los profesores.

PALABRAS CLAVE: Educación física. Currículo de São Paulo. Carrera docente. 


\section{INTRODUÇÃO}

No ano de 2008, foi criada, por intermédio da Secretaria de Educação do Estado de São Paulo, a Proposta Curricular para a disciplina de Educação Física, ${ }^{1}$ documento que no ano de 2010 passou a se chamar Currículo do Estado de São Paulo (CEF-SP).

A Educação Física, como componente curricular deste material, encontra-se localizada na área de Linguagens, Códigos e suas Tecnologias, assumindo uma abordagem cultural.

Para sustentar a abordagem cultural de área, o documento utiliza-se principalmente de referenciais advindos da Antropologia Social e da Fenomenologia e constrói três conceitos teóricos que permeiam todo o material e consolidam o entendimento de Educação Física.

O primeiro conceito é o de Cultura, definida como "urdidura de muitos fios que se interligam constantemente e que respondem às diferentes formas com que nos relacionamos com as coisas do mundo, com outros seres humanos e com os objetos". 2:28 Muito semelhante à Geertz, ${ }^{3}$ quando o mesmo define cultura como sendo um conjunto de "teias de significados".

Além do conceito de Cultura, o Currículo também pauta a sua discussão em outros dois conceitos, Cultura de Movimento e Se-Movimentar. Nesse sentido a Cultura de Movimento é definida no documento ${ }^{2: 225}$ como:

[...] Conjunto de significados/sentidos, símbolos e códigos que se produzem e reproduzem dinamicamente nos jogos, esportes, danças e atividades rítmicas, lutas, ginásticas etc., os quais influenciam, delimitam, dinamizam e/ou constrangem o Se-Movimentar dos sujeitos, base de nosso diálogo expressivo com o mundo e com os outros.

Com relação a esse conceito o currículo de São Paulo baseia-se principalmente em uma abordagem antropológica, que atribui à cultura uma dimensão simbólica e dinâmica. Além disso, é possível observar certa relação com o autor Kunz ${ }^{4}$ quando o mesmo diz preferir utilizar "Cultura de Movimento" ao invés de "Cultura Corporal", visto que esse segundo conceito cria a possibilidade de entendimento de que além de uma cultura corporal 
poderiam existir outras culturas, como por exemplo, a intelectual, reforçando a dicotomia corpo/mente que ainda se mantém na área de Educação Física.

Já com o conceito de Se-Movimentar, originalmente desenvolvido por Kunz ${ }^{5 ; 4}$ pretende-se destacar o sujeito do movimento, colocando o aluno como criador dos próprios movimentos. O autor ainda destaca uma concepção dialógica, em que o movimento é considerado como uma forma de diálogo subjetiva entre o homem e o mundo. Dessa forma, essa abordagem contrapõe a ideia de análise mecânica do movimento, que o descontextualiza do sujeito, muito característica na biomecânica e na fisiologia. Desse modo, Se-Movimentar é definido no Currículo ${ }^{2: 225}$ como:

[...] Expressão individual e/ou grupal no âmbito de uma cultura de movimento; é a relação que o sujeito estabelece com esta cultura a partir de seu repertório (informações/conhecimentos, movimentos, condutas etc.), de sua história de vida, de suas vinculações socioculturais e de seus desejos.

Desde a implementação do material algumas pesquisas foram desenvolvidas ${ }^{6-9}$ a fim de investigar os impactos que a implementação trouxe para a Educação Física Escolar. Três desses trabalhos buscaram ouvir os professores da rede tentando analisar sua compreensão sobre o material. No entanto, nenhum dos trabalhos buscou relacionar esta compreensão com o momento da carreira docente vivida pelos professores entrevistados.

$\mathrm{Na}$ tentativa de contribuir com novas observações sobre o tema, neste estudo tivemos como objetivo geral analisara compreensão dos professores da Rede Estadual de São Paulo sobre o Currículo de Educação Física vigente e, de forma específica, considerar a relação desta compreensão com as etapas da carreira docente dos professores.

\section{A CARREIRA DOCENTE}

As pesquisas em Educação Física Escolar apresentam, majoritariamente, uma discussão profunda em relação às abordagens, conteúdos, a prática pedagógica dos professores. Por outro lado, pouco se discute a respeito do desenvolvimento da carreira docente, suas características, os fatores que podem influenciar nesse processo e, sobretudo, como o momento vivido pelo professor interfere nos seus conhecimentos e, principalmente, em sua prática pedagógica. 
Como referencial para esta discussão nos baseamos nos trabalhos de Huberman ${ }^{10}$ sobre o ciclo de vida profissional dos professores. Para ele, o docente não constrói a sua carreira de forma linear, ela vai se moldando de acordo com as experiências com as quais ele vai se deparando, as relações com as instituições (universidade, escola), assim como com outros profissionais da área e também com os alunos. Dessa forma consideramos que as relações sociais e culturais influenciam no processo de construção da carreira docente.

O autor, levando em consideração certas características da carreira, delimita algumas etapas presentes no desenvolvimento, não como forma de generalização, mas por encontrar certas regularidades no desenvolvimento profissional dos professores. Daremos ênfase neste trabalho somente às três primeiras etapas descritas pelo autor.

A primeira etapa seria a "entrada na carreira", que costuma variar de 1 a 3 anos de docência, geralmente marcada pelas sensações de sobrevivência, descoberta e exploração. De acordo com o autor, algumas características podem ser encontradas nesse momento da carreira: ${ }^{10: 39}$

[...] o tatear constante, a preocupação consigo próprio ("Estou-me a aguentar?"), a distância entre os ideais e as realidades quotidianas da sala de aula, a fragmentação do trabalho, a dificuldade em fazer face, simultaneamente, à relação pedagógica e à transmissão de conhecimentos, a oscilação entre relações demasiado íntimas e demasiado distantes, dificuldades com alunos que criam problemas, com material didático inadequado, etc.

A segunda etapa, chamada de "estabilização", varia de 4 a 7 anos, marcada pelo aumento de comprometimento e responsabilidade com o ser docente.

A escolha de uma identidade profissional implica a renúncia, pelo menos por um determinado período, a outras identidades. ${ }^{10: 40}$

É nessa fase que o professor, levando em consideração as suas experiências anteriores, decide por seguir definitivamente nesta carreira ou renunciar. São muito comuns os sentimentos de conforto e liberdade com a definição das práticas pedagógicas, aos objetivos da disciplina, assim como em relação aos alunos. 
O autor ainda cita uma terceira fase chamada de "diversificação", que varia de 8 a 25 anos. Os professores desta fase: ${ }^{10: 41-42}$

[...] lançam-se, então, numa pequena série de experiências pessoais, diversificando o material didático, os modos de avaliação, a forma de agrupar os alunos, as sequências do programa, etc. [...] seriam, assim, os mais motivados, os mais dinâmicos, os mais empenhados nas equipas pedagógicas.

Huberman $^{10}$ ainda descreve em seu estudo outras etapas da carreira docente. Não avançaremos para além destas três citadas, devido às características dos professores que atuam na rede estadual de São Paulo, visto que a grande maioria se concentra nestas etapas. Por outro lado, não descartamos a possibilidade de outros trabalhos na área de Educação Física Escolar se aprofundarem nas demais etapas.

\section{METODOLOGIA}

Utilizamos como metodologia a pesquisa qualitativa com entrevistas semi-estruturadas. ${ }^{11}$ Entendemos por entrevista semi-estruturada "aquela que parte de certos questionamentos básicos, apoiados em teorias e hipóteses, que interessam à pesquisa, e que, em seguida, oferecem amplo campo de interrogativas". 11:146 Caracteriza-se também por garantir a participação ativa do entrevistador, bem como possibilitando maior liberdade do pesquisador. "Desta maneira, o informante, seguindo espontaneamente a linha de seu pensamento e de suas experiências dentro do foco principal colocado pelo investigador, começa a participar na elaboração do conteúdo da pesquisa". ${ }^{11: 146}$

Para o desenvolvimento das entrevistas, entramos em contato com a Diretoria de Ensino Campinas Leste (DECL), que coordena o trabalho dos professores de Educação Física das escolas estaduais na região leste de Campinas, para conseguir a autorização para a realização da pesquisa.Com a concessão da autorização da DECL, enviamos a mesma junto ao projeto de pesquisa para analise do Comitê de Ética em Pesquisa da Unicamp Campus Campinas (CEP), que aprovou a realização da pesquisa.

Como critério de escolha dos entrevistados, definimos que os professores teriam que ter anos de carreira docente distintos uns dos outros, para tentar abranger as etapas da carreira

\begin{tabular}{|l|c|c|c|c|c|c}
\hline CC Conexões & Campinas, SP & v. 14 & n. 1 & p. 87-103 & ján./mar. 2016 & ISSN 1983-9030
\end{tabular}


docente presentes no estudo de Huberman. ${ }^{10}$ Para isso procuramos três professores que confirmassem o uso do CEF-SP e que tivessem entrado na carreira docente em anos distintos, cada um representando uma das etapas da carreira docente.

O professor 1 iniciou sua carreira no ano de 2012 (Entrada na carreira), possuindo na época da pesquisa dois anos de exercício; o professor 2 iniciou a carreira no ano de 2010 (Estabilização), possuindo cinco anos de exercício; e, por fim, o professor 3 iniciou a carreira no ano de 2002 (Diversificação), estando com 13 anos de exercício da profissão.

As entrevistas tinham perguntas divididas em quatro eixos, sendo:

(1) Caracterização do professor;

(2) Formação profissional;

(3) Carreira docente;

(4) Compreensão sobre o currículo.

O material referente à pesquisa realizada contou com gravações de áudio durante as entrevistas que foram transcritas em seguida. As gravações e transcrições foram utilizadas para a interpretação presente nesse estudo.

O material oriundo das entrevistas com os professores foi analisado considerando o objetivo da pesquisa, ou seja, a compreensão dos professores sobre o currículo de Educação Física do Estado de São Paulo, porém em sua relação específica com as etapas da carreira docente, descritas acima a partir das contribuições de Huberman. A intenção foi a de cotejar essas duas categorias, mostrando como a compreensão dos professores sobre o currículo depende também da etapa da carreira docente.

Todos os professores participantes tiveram contato com o Termo de Consentimento Livre e Esclarecido (TCLE) consubstanciado pelo CEP, tornando-se cientes sobre a natureza da pesquisa, seus objetivos, métodos, benefícios previstos, potenciais riscos e incômodos que a pesquisa acarretaria e aceitando a participação. 


\section{INTERPRETAÇÃO}

A partir da síntese de todas as entrevistas, percebemos que algumas características das etapas da carreira dos professores eram encontradas também na literatura utilizada no trabalho. Por outro lado, percebemos a existência de outros fatores que precisam ser melhor analisados, pois também influenciavam tanto a construção da carreira docente quanto a sua compreensão sobre o currículo da Educação Física. Tentaremos abordar alguns desses temas, começando pela questão da carreira docente, até chegar à utilização e compreensão do material.

De acordo com as entrevistas percebemos o desenrolar da carreira dos professores. $\mathrm{O}$ professor 1 fala muito sobre as dificuldades que enfrenta no cotidiano de trabalho, como por exemplo a sua falta de repertório, a relação com os alunos, muito próxima ou muito impositiva. Isso faz com que a aula muitas vezes saia do seu controle, gerando frustrações.

O professor 2 também fala sobre seus sentimentos de frustração durante a sua entrada na carreira, afirmando que já se sentiu desmotivado por causa dessas situações. De acordo com Huberman ${ }^{10}$, essas dificuldades de atuação são comuns no início da carreira, uma vez que o professor necessita confrontar constantemente o que havia estudado no curso de formação com seu cotidiano de trabalho, para assim construir a sua prática pedagógica.

O professor 2, diferentemente do 1, relata que passou por esses momentos principalmente durante os estágios realizados durante a sua graduação e no primeiro ano de docência, mas atualmente, com cinco anos de carreira, se sente motivado e seguro para continuar exercendo a docência. Visualizamos nesse caso que a atuação durante a graduação possibilitou que a entrada da carreira fosse mais facilitada.

Em concordância, os três professores mostram-se preocupados com a qualidade das aulas, desenvolvendo diversas estratégias para repensá-las.

O professor 1 afirma que utiliza um diário para fazer anotações sobre as aulas e diz que muitas vezes compra alguns materiais com o próprio dinheiro. Todos destacam a questão

\begin{tabular}{|l|c|c|c|c|c|c}
\hline CConexões & Campinas, SP & v. 14 & n. 1 & p. 87-103 & ján./mar. 2016 & ISSN 1983-9030
\end{tabular}


da pesquisa na internet e em outras fontes como forma de renovar a sua prática pedagógica. Nesse sentido, mesmo o professor 1 mostrando certas características da primeira etapa, percebemos que ele se encontra em um momento de transição para a segunda etapa, visto a preocupação que tem com as aulas e os alunos. Essa é uma característica marcante na vida do professor, destacada por Huberman, ${ }^{10}$ que afirma que é nesse momento que o professor assume realmente as responsabilidades da sua profissão.

O professor 3 fala pouco sobre a sua entrada na carreira, talvez pela distância dos anos iniciais de atuação. Dentre os seus relatos destacamos a questão da diversificação (característica marcante da terceira etapa).

Em vários momentos o mesmo diz que está sempre tentando trazer conteúdos novos, novas formas de dar aula, estratégias e atividades.

Assim como o professor 2 diz sobre o sentimento de segurança durante a atuação profissional, o professor 3 mostra que está sempre tentando inovar a sua prática pedagógica, dentro das suas capacidades.

Um segundo tema citado por todos os professores, que pode ter influência na construção da carreira docente, foi a relação do mesmo com a rede estadual de São Paulo.

Todos os professores mostraram-se descontentes com a forma como o professor é tratado, principalmente nos primeiros anos de atuação.

Destacamos a questão da alta rotatividade nas escolas, impedindo o desenvolvimento de conteúdos em longo prazo, assim como maior profundidade nos relacionamentos entre professor e aluno, professor e escola.

Outra queixa decorrente tem a ver com o pequeno investimento da rede estadual nos materiais e espaços, fazendo com que o professor muitas vezes seja impedido de trabalhar com uma gama diversificada de atividades. 
O professor que ingressa em uma rede com tamanho desinvestimento tende a ter problemas no desenvolvimento da sua carreira, uma vez que, para Huberman, ${ }^{10}$ as relações socioculturais com as quais o professor tem contato nesse processo são fundamentais para a construção da sua atuação. Essa problemática aparece nas falas, por exemplo, dos professores 1 e 3 .

O descontentamento com a rede estadual, além de influenciar a carreira docente, reverbera também na relação do professor com o Currículo.

Todos os três professores dizem que, apesar do documento dar um norte para o professor, muitas coisas propostas não são realizadas devido a diferença entre a realidade pensada e a realidade da escola. O professor 2 diz que usa o currículo em certos momentos, em outros a sua utilização fica inviável. Em concordância com esse aspecto, o professor 3 revela ainda insatisfação quanto a falta de diálogo da equipe criadora do material e os professores da rede.

Esses comentários tornam-se relevantes porque são reflexos de uma implementação desorganizada realizada anos atrás. Apesar da premissa de reestruturação e organização na área da educação, $\operatorname{Rocha}^{8}$ nos mostra que o processo de implementação deste material não se deu de forma bem planejada. $\mathrm{O}$ autor relata ainda as descontinuidades do processo desde os primeiros dias do ano de 2008 até a consolidação do Currículo do Estado de São Paulo, em 2010.

Apesar de todos os aspectos negativos levantados até então, um terceiro tema que nos chama a atenção é a questão da importância dada ao material pelos professores, visto que, de acordo com a etapa da carreira, ela parece ter certas particularidades.

O professor 1 relata que o documento tem sido muito importante para a reflexão da sua prática pedagógica, pois ali é possível encontrar uma variedade de estratégias e atividades para desenvolver os conteúdos. Segundo ele, além do diário das aulas, o documento é uma das fontes de pesquisa que contribui para a melhora da sua atuação, assim como na qualidade das aulas. 
Nesse mesmo sentido o professor 3 também ressalta a contribuição para a qualidade das aulas, mas, diferentemente do professor 1, não parece recorrer ao documento para tentar consolidar a sua prática pedagógica, mas somente para tentar acrescentar novas ideias às suas aulas, como se estivesse utilizando um manual de atividades.

Essa mesma diferença de importância dada ao material aparece no quarto tema que nos chamou a atenção, presente em um trecho da entrevista com o professor 1 sobre as reuniões de formação continuada na escola. Para ele, discutir acerca do currículo é fundamental para o seu processo de reflexão da prática pedagógica, mas, ao se reunir com outros professores mais antigos do que ele, desmotivados pelas condições de trabalho e pela própria carreira, as reuniões não fluíam, havendo pouco interesse e preocupação em um estudo do material.

Esta situação mostra que as etapas da carreira podem influenciar no sentido dado ao material, utilizando-o como base para se apoiar e se constituir como professor ou somente como um livro de atividades.

Entendemos que todos os aspectos levantados até então influenciam sobremaneira a forma destes professores construírem a sua carreira, dar aulas e sentido ao currículo. As diversas experiências aqui descritas durante as suas formações e relações de trabalho nas escolas tiveram relação com a construção das suas práticas pedagógicas assim como os saberes sobre o CEF-SP.

A partir desse cenário que tentamos montar relacionando

(1) as etapas da carreira docente,

(2) o que os professores falam sobre a rede estadual de São Paulo e

(3) sentidos dados ao currículo de modo geral, tentaremos discorrer acerca da compreensão mais específica do material, principalmente sobre a questão dos conceitos Cultura de Movimento e SeMovimentar dos alunos. 
Quando perguntados especificamente sobre o que eles compreendem do currículo, percebe-se que a linguagem utilizada para dar as respostas não foi a mesma encontrada no documento, mostrando que o professor se apropria daqueles saberes de acordo com as suas experiências na formação e na atuação profissional.

Os professores 1 e 2 reconhecem que a Educação Física, a partir da perspectiva do currículo, trata dos conteúdos ginástica, lutas, jogo, esporte, atividades rítmicas.

O professor 1 ainda se aprofunda mais que o 2, dizendo que esses conteúdos devem ser tratados de forma progressiva, fazendo com que o aluno tenha os primeiros contatos com eles, se aprofunde neles e entenda também o contexto daquela manifestação, embora recorra a uma visão restrita da abordagem cultural da área, visto que não contempla o aspecto simbólico.

O professor 3, por outro lado, fala que a principal função da Educação Física é mostrar para o aluno uma diversidade de práticas possíveis de atividade física, fazendo com que ele amplie a sua visão para chegar a ter uma boa qualidade de vida. Essa fala é muito semelhante à utilizada pela abordagem da saúde que valoriza; sobretudo a perspectiva biológica do ser humano.

Sobre o conceito de Cultura de Movimento, o professor 2, sem se aprofundar em detalhes, diz que seria tudo aquilo que o homem produz, e que é papel da Educação Física apresentar essas construções para os alunos. Os professores 1 e 3 não falam em momento nenhum sobre Cultura de Movimento, mas o 1 se aprofunda mais do que o 3, lembrando dos eixos de conteúdo presentes no currículo, que permitem ao professor trabalhar com os conteúdos e contextualizar historicamente, trazer discussões de gênero e de regiões em que são praticados.

O professor 2 traz à tona, sobre o tema da cultura, o que parece ser uma divergência em relação ao currículo. Ele expressa dúvida ao falar se deve valorizar a cultura da comunidade dos alunos ou ampliar e mostrar outras culturas. Nesse sentido percebemos uma leitura pouco aprofundada do currículo, uma vez que o mesmo não se restringe a 
nenhum dos polos, afirmando que a Cultura de Movimento deve ser apresentada para o aluno valorizando a cultura local, mas também em um plano maior.

Sobre a questão do Se-Movimentar do aluno, o professor 3 afirma que o aluno se expressa nas práticas, se movimenta e não fica sedentário, não fica só observando. Já o professor 2 afirma que o Se-Movimentar do aluno deve ser incentivado nas aulas, para que ele cresça e seja capaz de praticar e valorizar a atividade física em sua vida. O professor 1 reconhece que por momentos exige dos alunos que o movimento seja executado de uma certa forma, mas que entende que o aluno deve experimentar e descobrir a sua própria forma de movimento.

A partir desses dados, percebemos que o professor 1 parece ter a compreensão um pouco mais ampliada do conceitos teóricos do CEF-SP, mas, de modo geral, a compreensão dos professores ainda é muito superficial.

Com relação ao conceito de Cultura de Movimento, percebemos algumas mudanças, se compararmos com os estudos de Amusquivar ${ }^{6}$ e Silva et al., ${ }^{9}$ no qual poucos professores justificavam a presença da Educação Física na escola a partir de uma abordagem cultural. Os professores aqui entrevistados, por outro lado, parecem começar a falar mais sobre cultura para justificar a disciplina.

O conceito de Se-Movimentar, por outro lado, ainda é pouco entendido. A compreensão referente a essa abordagem filosófica da área parece ser ainda de difícil acesso por parte dos professores. Assim como nos estudos já citados, o Se-Movimentar é lembrado muito mais a partir de uma perspectiva biológica, do não sedentarismo, qualidade de vida, do que no plano da linguagem e diálogo com o mundo.

Como já mencionado, dados semelhantes foram encontrados na pesquisa de Amusquivar ${ }^{6}$ e, de acordo com a autora, uma das possíveis influências seria a formação dos professores. Concordamos com a afirmação da autora, pois, ao analisar a formação dos três professores aqui entrevistados, percebemos que as respostas dadas por eles vão ao encontro das experiências descritas sobre o curso de graduação que cursaram. 
O professor 1 teve uma formação mais ampla em relação às abordagens de Educação Física, tendo contato com o currículo e com leituras de outras abordagens, mostrando uma primeira apropriação do assunto. No entanto, ao longo do seu curso, a principal ênfase dada pelas disciplinas constituía de discussões teóricas. A partir disso podemos tirar dois pontos fundamentais, a formação profissional influenciou na sua entrada na carreira, limitando o seu repertório de atividades, mas por outro lado deu base para ler e interpretar o currículo de forma diferenciada dos outros dois professores.

O professor 2, de acordo com a entrevista, teve uma formação que enfatizou aspectos biológicos e esportivos, assim como o professor 3. O contato que teve com o currículo foi bem superficial e somente no trabalho de conclusão de curso pôde ter mais contato com o material.

O professor 3 enfatizou que até receber o CEF-SP na sua escola, em momento nenhum ele teve contato com leituras que tratassem do conceito de Cultura de Movimento e nem do Se-Movimentar. Afirma que só tomou conhecimento dos assuntos lendo o documento e fazendo parte de um curso de especialização oferecido pela rede durante a implementação dos materiais.

\section{ALGUMAS CONSIDERAÇÕES}

Percebemos que muitas características da carreira descritas pelos professores dialogam com etapas estudadas no referencial deste trabalho. Foi possível enxergar também certo desenvolvimento na construção da prática pedagógica dos professores de Educação Física, não de forma linear, mas de acordo com as relações e experiências socioculturais com as quais cada um tomou contato.

A partir desse desenvolvimento destacamos que o início da carreira é marcado por momentos de dificuldades, mas também por um caráter mais sonhador do docente, em um segundo momento, após diversas experiências, as dificuldades parecem diminuir dando lugar a uma certa estabilização da prática pedagógica e, posteriormente, com o professor já mais maduro, aparece a questão da tentativa de diversificação, que, por sua vez, vai entrar em conflito com hábitos que acabaram se cristalizando com o tempo. 
Todas essas características parecem influenciar a relação dos professores com o currículo, visto que os sentidos dados, assim como as formas de utilização do material variam de acordo com as necessidades e problemáticas encontradas em cada uma das etapas da carreira.

Quando nos atentamos especificamente à compreensão dos professores a respeito dos conceitos teóricos presentes no currículo, foi possível perceber um entendimento pouco aprofundado sobre todos eles. Nesse aspecto não podemos desconsiderar o papel da própria rede estadual de São Paulo que, além de ter implementado o material com várias descontinuidades, não vêm oferecendo formação continuada e espaços do diálogo para que os professores possam discutir; estudar e compreender o Currículo profundamente.

Esses resultados demonstram que mais do criar uma proposta para as mais de 5000 escolas da rede, é preciso também se preocupar com a capacitação dos profissionais que utilizarão esse material, assim como com o desenvolvimento da sua carreira.

Por fim, apesar das etapas da carreira pouco influenciar na forma como cada um compreende os conceitos teóricos, percebemos que elas influenciam a forma como os docentes atuam e lidam com o Currículo no seu cotidiano.

Nesse sentido, consideramos que a perspectiva adotada neste trabalho, relacionando a compreensão dos professores com as etapas da carreira, permitiu avançar na análise dos impactos e da utilização do Currículo da Educação Física, visto que até então esses resultados não haviam aparecido em nenhum outro trabalho.

Parece-nos ainda que um aspecto fundamental para ampliar a análise dessa problemática é também considerar as experiências de formação profissional que cada um teve ao longo da vida, as características dos cursos de graduação, as possibilidades de continuar estudando o tema durante a atuação, entre outros fatores. 


\section{REFERÊNCIAS}

1SÃO PAULO (Estado). Secretaria da Educação. Proposta curricular do Estado de São

Paulo: educação física - ensino fundamental ciclo II e ensino médio. São Paulo, 2008.

${ }^{2}$ SÃO PAUlO (Estado). Secretaria da Educação. Currículo do Estado de São Paulo: linguagens, códigos e suas tecnologias - ensino fundamental ciclo II e médio. 2. ed. São Paulo, 2011.

3GEERTZ, Clifford. A interpretação das culturas. Rio de Janeiro: LTC, 1989.

${ }^{4}$ KUNZ, Elenor. Transformação didático-pedagógica do esporte. Ijuí: Ed. da Unijuí, 1994.

${ }^{5}$ KUNZ, Elenor. Educação física: ensino \& mudanças. Ijuí: Ed. da Unijuí, 1991.

${ }^{6}$ AMUSQUIVAR, Solange Braguieri. A educação física na proposta curricular do estado de São Paulo: visão dos professores. 2010. 75f. Trabalho de Conclusão de Curso (Graduação) - Faculdade de Educação Física, Universidade Estadual de Campinas, Campinas, 2010.

${ }^{7}$ NEIRA, Marcos Garcia. A proposta curricular no estado de São Paulo na perspectiva dos saberes docentes. Revista Brasileira de Educação Física e Esporte, São Paulo, v. 25, p. 23-27, nov. 2011.

${ }^{8}$ ROCHA, Robinson Luiz Franco da. A prática pedagógica de educação física a partir do currículo de São Paulo. 2014. 187f. Dissertação (Mestrado em Educação Física) Faculdade de Educação Física, Universidade Estadual de Campinas, Campinas, 2014.

${ }^{9}$ SILVA, I. K.; SANTOS, B. R.; RODRIGUES JÚNIOR, J. C. A compreensão de professores sobre o currículo de educação física de ensino de São Paulo em comparação com a concepção de um dos autores do currículo. Conexões: revista da Faculdade de Educação Física da UNICAMP, Campinas, v. 12, n. 1, p. 59-84, jan./mar. 2014. 
${ }^{10}$ HUBERMAN, Michael. O ciclo de vida profissional dos professores. In: NOVOA, Antonio (Org.). Vidas de professores. 2. ed. Porto: Porto, 2007.

${ }^{11}$ TRIVIÑOS, Augusto Nibaldo Silva. Introdução à pesquisa em ciências sociais: a pesquisa qualitativa em educação. São Paulo: Atlas, 1987. 